\title{
An Urban Appalachian Community in Indianapolis: With Implications for Art Education Marjorie Cohee Manifold
}

I first became interested in immigrant Appalachian populations when assigned to teach art in an Indianapolis elementary school which served an urban Appalachian community. The problems peculiar to poor, urban students were fully evident in this population and seemed stubbornly resistant to change. It became apparent that traditional practices were not effective. This initiated a quest to better understand the local 10th Street Community, and resulted in research exploring the community's general characteristics, operant aesthetic attitudes, and perceived roles oi art and artists in the community. From these research findings, it is anticipated that more effective, population specific, art educational programs may be developed and implemented.

\section{The 10th Street Community}

Those persons who consider themselves part of the unique 10th Street community live on and around a short eastern stretch of this Indianapolis street. Residents express strong self-identification as "10th Streeters". As descendants of Appalachian born, urban immigrants, they are an "invisible minority" (Philliber, McCoy, \& Dillingham 1981) and the second largest minority of this midwestern city.

The predominant migration of Appalachians to the urban centers of the Midwest, including the city of Indianapolis, occurred as an economic necessity following World War II. Those who remain of this urban Appalachian population are now third and fourth generation members. Self-preserving characteristics and prejudice against Appalachian groups have made them vulnerable to discrimination and contributed to their impoverished conditions.

While not all 10th Streeters are native to or descendant from Appalachian sites, the characteristics of the 10 th Street community have been strongly colored and influenced by this population. Therefore, the urban Appalachian qualities were those which were examined and addressed in this descriptive study.

\section{Methods}

in order to gain access to the community, I became involved in a local retail business venture which required daily, multi-level interactions with

Marilyn Zurmuehlen's Working Papers In Art Education 1994-1995 
persons from the community. Thus, gatekeepers, individuals providing access to the inner workings of the community, came from relationships of trust forged with members of the 10th Street community.

Initial data was collected through observations of behaviors, interactions, and conversations. Interviews were unstructured, informal, and open ended. Conversations, interviews, and observations were recorded as notations made at the end of the day or after significant events. Once a sense of comfort and trust seemed in place between me as the researcher and community members, a purposeful sample of artists and art informants were defined. Interviews became increasingly structured, focusing on specific issues of concern. These later interviews were recorded in notes taken during events, or recorded on tapes which I later transcribed.

On-site data collection was followed by a four month period of data coding, categorization, and analysis. Procedures followed for this study were adapted from suggestions and guidelines given by Krathwohl (1993) and Bodgan and Biklen (1982). Those interviewed included male and female individuals ranging in age from teens to octogenarians. Following are descriptions of four groups of persons interviewed:

Group A. Artists identified by community consensus.

Group B. Artists who identified themselves as people who made art.

Group C. Artists informants. These individuals fit the criteria of Krathwohl (1993) as "marginal persons who have less stake in the status quo or are not constrained by it" (p. 327). The individuals in this category were classified thus, because they were former 10th Streeters, or other urban Appalachians, not residing in the 10th Street community during the time of the interviews.

Group D. Non-artist individuals. These were individuals living in the 10th Street community who gave information regarding art and artists in the community, but were neither considered by others nor themselves to be producers of art.

Groups A, B, and C consisted of 3 individuals each. Group D included conversations or interviews with 42 individuals. The behaviors and interactions of approximately 30 to 40 additional persons, the exact number was not recorded, were observed and noted. The conclusions drawn from these observations served as corroborative data.

\section{Findings}


Analysis of the data produced two large calegories: The artist and aesthetic preferences. Subcategories within these categories, drawn from the data, are described as follows:

\section{The Artist}

1. The artist, according to the 10th Street definition, is a person who "draws", "paints pictures," or "makes things" (art objects).

2. The artist is rarely defined only by the role of artist. The artist will also be a wife/mother, husband/father, waitress, factory worker, mechanic, etc., with these roles considered of equal or greater importance to the individual's identity than the role of artist.

3. The behavior the artist displays is a determinant factor in whether he or she receives community recognition as an artist. Those who display "appropriate" artist characteristics are likely to be rewarded by the praise and respect of community members. Those who do not, regardless of the quality of their. production, are unlikely to be valued as artists. Two artistic characteristics were identified by the participants in this study: (a) modesty about his or her talent with disinterest in personal glory which would elevate him or her above other members of the community, and (b) willingness to create work for benefit of the family or the community.

\section{Aesthetic Preferences}

1. According to 10th Street explanations there is a preference for useful art objects, followed by an interest in art images with personal, religious, or seasonal referents.

2. Realism is the preferred mode for depicting figural subjects.

3. There is a preference for affordable techniques and accessible, inexpensive, and /or indigenous materials.

4. Craftspersonship and realism are quality measures that take precedence over originality.

5. There is an appreciation for bright, contrasting colors, and for materials which imitate expensive materials such as velvets, metallic labrics, leather, and rhinestones.

6. Craft shows, bazaars, and street fairs were mentioned as places where one could go to see art. The art museum was not mentioned as a place where art could be viewed.

\section{Discussion}

In an attempt to further examine the urban, Appalachian, 10th Street community, I will interweave the role of the artist and aesthetic attitudes, as 
described by the participants, with general characteristics of this population. Then I will derive some general classroom implications from this analysis.

\section{Familism and Individualism}

The social organization system familiar to the Appalachian culture is dominated by family-kinship relations (Wagner 1973). The family kinship or familism relationship, was expressed in the often heard statement, "10th Streeters take care of their own." The indication was one of community pride and a self-reassurance that in times of adversity the community would serve as a safety net. "Squirrel" (Group B), a single homeless, urban Appalachian Cherokee suffering from alcoholism, was never observed to go without a daily meal, suitably warm clothing, or a place to spend the night in inclement weather. Alcoholism, though viewed as an unfortunate choice of behavior, was seen as a kind of individuality, and thus warranted neither condemnation nor interference. It was, frankly, "nobody's business" except Squirrel's. The kindness of community members was returned with gifts of jewelry crafted by Squirrel from found objects and beads in what he called his "Indian style." In giving his art as gifts to the community family, Squirrel displayed a required artistic trait of creating work for the benefit of the community. This was seen as appropriate community behavior.

For 10th Streeters, artistic behavior must be community appropriate, but individualism allows a person, in terms of aesthetic choices, to be as outrageous or anti-social, by mainstream standards, as he or she wishes. Tattoos are a favorite body decoration and admired art form among adolescent and young adult 10th Street males and females. Chosen motifs for tattoos range from Confederate flags to elaborate dragons. Gang referents also are becoming popular motifs.

\section{Valuing and Seeking Personal Relationships}

Established trust is vital to successful interactions with members of this community. In personal relationships individuals are inclined to be trusting but they are suspicious of anything that threatens to compromise their independence (Smathers, 1970). The educational institution is seen as an uninvited intruder in the urban Appalachian community. Relatives of school aged children do not see it as their responsibility to establish rapport with school personnel. Rather, the onus is on the educators as outsiders and human embodiments of the educational institution to make their intentions known to the members of the community. An example of the chasm between school and community may be recognized in the prevalent inability of 10th Street parents to relate the names of their children's teachers. Two teachers who were known by name were described as "real nice," or "friendly." These 
teachers also participated in out of school activities with their students, and showed interest in community members and community affairs.

\section{Have a Limited Time Perspective}

Because life in a hostile environment is tenuous, requiring immediate reaction to non-predictable, ever changing challenges, long range planning often makes little sense in an urban Appalachian community. Personal family needs require hands on and immediate responses. The ability to fulfill needs by creatively adapting available materials, requires immediate vision not long range plarining. In art classes this ability is reflected by an appreciation for quick and easy projects which can be taken home and enjoyed immediately.

Techniques or products which require expensive, commercially made materials and equipment present unrealistic, unattainable possibilities. Unless access to kilns, printing presses and other equipment and materials are made practically available, traditional arts and crafts will not be pursued beyond the classroom. Those persons driven to create art will make their art out of found or unconventional materials. Both "Squirrel" (Group B) and "Falcon" (Group C), for example, admit to searching through trash dumpsters to gather much of their material for artmaking.

\section{Strongly Identify with Place}

One of the surprising aspects of the 10th Street population is their impassioned affection for a geographic area which appears oppressively unattractive to those outside the community. Harold's (Group D) comment, "I went away from 10th Street for awhile, but I had to come back. I love 10th Street! Ain't no place like it in the world!" is typical of the sentiments expressed. Clearly, the urban Appalachian standard for beauty is dependent upon affective rather than formal criteria.

\section{Share a Non-Verbal Heritage}

Responses to events appear to be subjective and emotional rather than objective and logical. At this intuitive level, ability to verbalize responses remains very naive (Southward, 1986). Hamblen(1984) suggests that it may be the use of non-traditional speech patterns which hampers the ability of non-Appalachians to discuss art and aesthetic concepts in formal terms. What we perceive as inability to verbalize aesthetic concepts may merely be an inability to speak in the standard formal aesthetic lingo. These non-verbal characteristics should not be mistaken for an inability to understand sophisticated aesthetic concepts. There appear to be definite community standards by which art and art objects are measured. That these standards

Marilyn Zurmuehlen's Working Papers In Art Education 1994-1995 
are communicated, whether verbally or non verbally, and understood, is indication of potent aesthetic cognition.

\section{Withdraw from Threatening or Frustrating Situations \\ Early studies of the urban Appalachian population, (Wagner1973)}

indicated a tendency to withdraw rather than react aggressively or with hostility, when confronted with uncompromising or difficult situations. While older urban Appalachians may seek to avoid direct confrontation, younger urban Appalachians find it increasingly difficult to do so. Many use visual symbols and artistic expression to overtly display their increasingly defiant stance against dominant institutions and power structures of society. June (Group D) told about the community's frustration when a local school was closed and use of the empty building for community activities was denied. When the school officials remained unresponsive to the community protests the frustration was acted out by adults and youngsters who "sneaked in that night and graftiti-ed (the abandoned school building) up real good!"

\section{Adhere to Gender Specific Roles}

The initial migration of Appalachians to cities was motivated by a neөd for the male member to find work. This move significantly affected the traditional role of the Appalachian female. In her mountain environment, her contribution to the household economy came from her interactive work with the environment. She was the one who cultivated the land, tended the garden, milked the cows, and was mother and nurturer (Ganim, 1986). Relocated in the city, women's contributional opportunities were limited. Unable to find satisfactory avenues for integrating needs of her family, with her own personal needs and resources, a tragic number of urban Appalachian women interviewed expressed low self esteem, hopelessness, and self destructive behaviors.

Lori Anne (Group A) was a woman who had reconciled a culturally dictated role with personal and environmental resources. Her strong maternal character found expression in her voluntarily assumed role of foster mother to several community youths in need, and in her production of art, particularly needle arts, which she made to clothe herself and her family, beautify her home, and give as gifts to others.

The male roles in the community of being financial providers, meant that males were more likely than fernales to make art as a commodity for economic benefit. Men were found to be tattoo artists, sign painters, jewelry makers, and portrait artists whose art could be exchanged for cash or goods. 


\section{Art Educational Implications}

The following is an outline of suggestions for art teachers addressing the urban Appalachian student's art education in terms of content and methodology. The suggestions are categorized as in the previous section and are implied by the findings of the community attitudes and ideas about art and artists, and the general characteristics of the community.

\section{Familism and Individualism}

1. Balance opportunities for creating art as personal expression with opportunities to learn art techniques for creation of useful, shareable art. 2. Use and discuss art exemplars from cultures which create community art, as well as, exemplars of personal expression.

3. Allow co-operative and small group work and projects.

4. Use a non-authoritarian teaching style which shifts the responsibility for behavior to the student. This is more likely to gain appropriate response from students who value individuality (Borman et al. 1978) within the boundaries of community defined propriety. The community of students should become the encouraging force for maintaining behavioral property.

Value Personal Relationships/Suspicious of Institutions 1. Share your (artist/art teacher) art skills with the community.

2. Invite local artists to share their aesthetic ideas, language and skills with students in the classroom.

3. The artist in residence concept is one which presents possibilities for bridging the gap of trust between school and community. Local artists as well as mainstream artists should be included in this program.

4. Find out when local festivals or art events are being held and plan to participate by including an exhibit of student work. Also display and share your own work.

Have Limited Time Perspectives

1. Encourage art making of both immediate and long term projects.

2. Emphasize the instruction of good craftspersonship.

3. Avoid arbitranily set time frames for completion of work. Rather, emphasis should be on completion of art which demonstrates satisfactory visual solutions and an appropriate degree of technical excellence regardless of the time this requires.

\section{Strongly Identify with Place}

1. Be cautious of pushing environmental beautification programs without negotiation with community members. The concept of beauty must be 
negotiated, and there must be assurance that improvements will not result in unacceptable change of the sense of place.

2. Community resources should be explored for materials which might be used in student art making.

3. Encourage the study of local architecture, spaces, and artifacts.

\section{Non-Verbal Behavior}

1. Begin art criticism exercises at the present level of the student and progressively, by building from one concept to another, raise the student to the goal level (McFee 1969). Moreall and Loy (1989) suggest, for example that popular mass produced commercial artifacts be compared to aesthetically acclaimed exemplars.

\section{Withdraw from Threatening Situation}

1. Be aware that aesthetic preferences of urban Appalachians differ from mainstream preferences.

2. Do not avoid correction of behavior or guidance of ideas, but approach art activities and instruction in such a way that the student does not feel that his or her aesthetic sensibilities have been insulted, devalued, or threatened. 3. Art presents a vehicle for social comment and outrage. Art teachers have a unique opportunity to instruct young urban Appalachian students in socially acceptable, yet powerful and empowering, expressive art language.

\section{Gender Specific Role}

1. In guiding art students from this population, it would be helpful for the art teacher to be aware that parents are concerned that children of both sexes consider participation in family and community life as more important than personal self-sacrifice in pursuit of professional careers, including art careers. Art taught in the classroom should not deny or subvert this family/community goal. Art as craft and communication, as well as art for arts sake, should be validated.

2. Art should not be categorized as strictly female or male appropriate. The necessities of economic survival in the urban landscape require a blurring of traditional gender roles. Therefore, both male and female students should be given options for increasing their productive/creative potentials.

\section{Future Research}

The descriptive study thus presented, is the first part of a two part investigation. I will next attempt to look at two populations of transplanted Appalachians in rural Southern Indiana. These rural Appalachian populations will be examined and contrasted and compared with urban Appalachian populations to determine similarities and differences in art attitudes as well as 
general characteristics. It is intended that the investigation will culminate in practical implications for development of effective art educational programs addressing the needs of both these Appalachian populations who settled in rural and urban areas of the Midwest. It is also hoped that generalizations from these investigations can be applied to populations of diverse students in a variety of contexts.

\section{References}

Bogdan, R.C. \& Biklen, S.K. (1982). Qualitative Research for Education: An Introduction to Theory and Methods, Boston, MA: Allyn \& Bacon.

Ganim, C. (1984). Herself: Women and Place in Appalachian Literature, Appalachian Journal, 13, 258-274.

Hamblen, K.A. (1984). The Culture of Aesthetic Discourse (CAD:Origins, Contradictions and implications, The Bulletin of the Caucus on Social Theory and Art Education, 4, 22-24.

Krathwohl, D. R. (1993). Methods of Educational and Social Science Research: An Integrated Approach, New York: Longman.

Philliber, W. H., McCoy, C. \& Dillingham, H. (Eds.) (1981). The Invisible Minority: Urban Appalachians, Lexington, KY: University Press of Kentucky.

Smathers, M. (1970). Suspicion and Community in Appalachia, in M. E. Glenn (Ed.), Appalachia in Transition (pp. 69-81). St. Louis, MO:Bethany Press.

Southward, B. (1986). Attitudes of Three Urban appalachian Teenagers Toward Selected Early Modern American Paintings, Bulletin of the Caucus on Social Theory and Art Education, 6, 8-18.

Wagner, T. E. (1973). Appalachian Migrant Studies in Cincinnati Public Schools. Unpublished Doctoral Dissertation, University of Cincinnati, Cincinnati. 